\title{
Modelling the life cycle of Salpa thompsoni
}

\author{
Natasha Henschke ${ }^{\mathrm{a}, *}$, Evgeny A. Pakhomov ${ }^{\mathrm{a}, \mathrm{b}, \mathrm{c}}$, Jürgen Groeneveld ${ }^{\mathrm{d}, \mathrm{e}}$, Bettina Meyer ${ }^{\mathrm{f}, \mathrm{g}, \mathrm{h}}$ \\ a Department of Earth, Ocean and Atmospheric Sciences, University of British Columbia, Vancouver, Canada \\ ${ }^{\mathrm{b}}$ Institute for the Oceans and Fisheries, University of British Columbia, Vancouver, Canada \\ ${ }^{\mathrm{c}}$ Hakai Institute, P.O. Box 309, Heriot Bay, BC VOP 1HO, Canada \\ ${ }^{\mathrm{d}}$ Institute of Forest Growth and Forest Computer Sciences, Technische Universität Dresden, PO 1117, 01735 Tharandt, Germany \\ e Helmholtz Centre for Environmental Research - UFZ, Department of Ecological Modelling, Permoserstraße. 15, 4318 Leipzig, Germany \\ ${ }^{\mathrm{f}}$ Alfred Wegener Institute Helmholtz Centre for Polar- and Marine Research, section Polar Biological Oceanography, Am Handelshafen 12, 27570 Bremerhaven, Germany \\ $\mathrm{g}$ Institute for Chemistry and Biology of the Marine Environment, Carl von Ossietzky University Oldenburg, 26111 Oldenburg, Germany \\ ${ }^{\mathbf{h}}$ Helmholtz Institute for Functional Marine Biodiversity at the University of Oldenburg, Germany
}

\section{A R T I C L E I N F O}

\section{Keywords:}

Salp

Salpa thompsoni

Southern Ocean

Zooplankton

Population dynamics

\begin{abstract}
A B S T R A C T
Salpa thompsoni is an important grazer in the Southern Ocean. It is found from the Subtropical Convergence southward to the coastal Antarctic Seas but being most abundant in the Antarctic Polar Frontal Zone. Low temperatures appear to negatively affect their development, limiting their ability to occur in the krill dominated high Antarctic ecosystems. Yet reports indicate that with ocean warming $S$. thompsoni have experienced a southward shift in their distribution. As they are efficient filter feeders, this shift can result in large-scale changes in the Southern Ocean ecosystem by increasing competitive or predatory interactions with Antarctic krill. To explore salp bloom dynamics in the Southern Ocean a size-structured $S$. thompsoni population model was developed with growth, consumption, reproduction and mortality rates dependent on temperature and chlorophyll $a$ conditions. The largest uncertainties in $S$. thompsoni population ecology are individual and population growth rates, with a recent study identifying the possibility that the life cycle could be much shorter than previously considered. Here we run a suite of hypothesis scenarios under various environmental conditions to determine the most appropriate growth rate. Temperature and chlorophyll $a$ were sufficient drivers to recreate seasonal and interannual dynamics of salp populations at two locations. The most suitable growth model suggests that mean $S$. thompsoni growth rates are likely to be $\sim 1 \mathrm{~mm}$ body length $\mathrm{d}^{-1}, 2$-fold higher than previous calculations. $S$. thompsoni biomass was dependent on bud release time, with larger biomass years corresponding to bud release occurring during favorable environmental conditions; increasing the survival and growth of blastozooids and resulting in higher embryo release. This model confirms that it is necessary for growth and reproductive rates to be flexible in order for the salp population to adapt to varying environmental conditions and provides a framework that can examine how future salp populations might respond to climate change.
\end{abstract}

\section{Introduction}

Salps are highly efficient grazers that are ubiquitous throughout the world's oceans (Alldredge and Madin, 1982). They are capable of rapidly filtering particles up to a rate of $100 \mathrm{~mL} \mathrm{~min}^{-1}$ (Harbison and Gilmer, 1976) and their grazing pressure regionally can exceed the total daily primary production (Dubischar and Bathmann, 1997). Salps can efficiently re-package small particles into larger ones, either through fast sinking, carbon-rich faecal pellets (Bruland and Silver, 1981; Perissinotto and Pakhomov, 1998a) or salp carcasses (Henschke et al., 2013; Smith et al., 2014). As a result, the influence of salp swarms on the biogeochemical cycles are substantial, contributing 10-fold more carbon to the seafloor than in areas without salp swarms (Fischer et al., 1988). However, this contribution is sporadic, and as the majority of studies are based on "potential" estimates there is uncertainty surrounding the total export flux produced by salps. A recent study suggests that recycling of salp faecal pellets in the epipelagic layer may be more common than previously believed, with only $\sim 13 \%$ of produced pellets captured in sediment traps at $300 \mathrm{~m}$ (Iversen et al., 2017).

Salpa thompsoni is the most prominent pelagic tunicate in the Southern Ocean, found from the Subtropical Convergence southward to the coastal Antarctic Seas but being most abundant in the Antarctic Polar Frontal Zone (Foxton, 1966; Pakhomov et al., 2002; Loeb and Santora, 2012). In recent decades reports indicate that $S$. thompsoni

\footnotetext{
* Corresponding author.

E-mail address: nhenschke@eoas.ubc.ca (N. Henschke).
} 
have experienced a southward shift in their distribution, resulting in increased abundance in the traditionally krill dominated high Antarctic (Loeb et al., 1997; Chiba et al., 1998; Pakhomov et al., 2002; Atkinson et al., 2004), and possibly linked to a decline in Antarctic krill abundance (Atkinson et al., 2004). However, the ability of $S$. thompsoni to proliferate in the high Antarctic remains limited as low temperatures $\left(<1{ }^{\circ} \mathrm{C}\right)$ negatively affect their reproductive development (Casareto and Nemoto, 1986; Chiba et al., 1999; Pakhomov et al., 2011; Ono and Moteki, 2013).

Salp growth rates have been found to vary depending on environmental conditions such as temperature and food availability (Heron, 1972; Deibel, 1982; Heron and Benham, 1984), however, "optimal" conditions promoting maximum growth are still unknown.

Salpa thompsoni growth rates have only been estimated from cohort analysis of length-frequency distributions (Loeb and Santora, 2012; Pakhomov and Hunt, 2017). Loeb and Santora (2012) analyzed S. thompsoni length-frequency distributions across 17 years (1993-2009) of austral summer (January-March) surveys near the Antarctic Peninsula. From evaluating changes in length modes between median survey dates, their growth rate estimates for $S$. thompsoni ranged from $0.15-0.52 \mathrm{~mm} \mathrm{~d}^{-1}\left(0.3-4.6 \% \mathrm{~d}^{-1}\right)$, with a 9 month generation time (Loeb and Santora, 2012). These long generation times suggest that for large abundances of $S$. thompsoni to occur, favorable conditions must have occurred for one or more previous years. More recently, Pakhomov and Hunt (2017) performed an Eulerian study in the Antarctic Polar Front to also estimate growth rates from length-frequency distributions. Samples were of high temporal resolution, every 2-3 days over an 18 day period in the 2012 austral summer (Pakhomov and Hunt, 2017). Calculated growth rates were on average 2-3 fold higher than the Loeb and Santora (2012) estimates; $0.2-3.3 \mathrm{~mm} \mathrm{~d}$ $\left(3.7-20.7 \% \mathrm{~d}^{-1}\right)$, suggesting generation times could be as short as 3 months (Pakhomov and Hunt, 2017). These high growth rates were similar to preliminary data collected during late summer in the Antarctic Polar Front in 2004 (von Harbou, 2009).

The variations in Salpa thompsoni growth rates highlight some of the limitations of using cohort analysis to determine growth rates. Cohort analysis of length-frequency distributions assume that each sample is from the same population, that growth rates are constant between sampling periods and that growth rate estimates are representative of all size distributions. These assumptions may be difficult to meet for organisms such as salps because their patchy nature and tendency to swarm during mating aggregations or from physical turbulence (Graham et al., 2001) mean it can be hard to find and track a representative population, especially if sampling periods are weeks/ months apart. Yet as salps are difficult to culture in the laboratory (Raskoff et al., 2003), there is a lack of experimental data on salp growth rates and no experimental data for $S$. thompsoni.

Considering this uncertainty in Salpa thompsoni growth rates, our aim was to develop a population model in which we could determine the most appropriate growth relationship by simulating $S$. thompsoni populations under various environmental conditions. We can use population modelling to enhance our understanding of the existing cohort analysis datasets by understanding the demographic drivers that underlie patterns in the data. While there are other mechanisms that influence population dynamics such as mortality and reproductive timing, here we focus on growth rates, as the ability for salps to respond rapidly to environmental fluctuations is a key method for their swarming success. To determine the most appropriate growth rate relationship we ran the model under a suite of growth rate scenarios (hypotheses) and compared outcomes with observed patterns in $S$. thompsoni populations in the Southern Ocean. The scenarios were: Hypothesis $1\left(\mathrm{H}_{1}\right)$ - Loeb and Santora (2012) "slow" growth rates; Hypothesis $2\left(\mathrm{H}_{2}\right)$ - Pakhomov and Hunt (2017) "fast" growth rates; and Hypothesis $3\left(\mathrm{H}_{3}\right)$ - "Proportional" growth rates where energy for growth and reproduction are constant proportions of consumption.

\section{Methods}

\subsection{Model description}

A size-structured Salpa thompsoni population model was developed to explore salp bloom dynamics in the Southern Ocean. The model follows cohorts of individuals at a daily time step. Three life stages are modelled: female blastozooids, male blastozooids and oozoids (Fig. 1). Female blastozooids will grow, and once sexually mature, they will release one oozoid embryo. At the end of sexual reproduction, functional females develop testes, transition into males and continue to grow while actively fertilizing young female blastozooids. Oozoids will grow and store energy for reproduction, and once enough energy is available, they will release up to four chains of genetically identical female blastozooid buds. The model uses eight state variables to simulate the life cycle: the number $\left(F_{N}\right.$, individuals (ind.) $\left.\mathrm{m}^{-3}\right)$ and size $\left(F_{C}, \mathrm{mg} \mathrm{C}\right)$ of female blastozooids, the number $\left(M_{N}\right.$, ind. $\left.\mathrm{m}^{-3}\right)$ and size $\left(M_{C}, \mathrm{mg} \mathrm{C}\right)$ of male blastozooids, the number $\left(O_{N}\right.$, ind. $\left.\mathrm{m}^{-3}\right)$ and size $\left(O_{C}, \mathrm{mg} \mathrm{C}\right)$ of oozoids and the amount of stored female $\left(F_{R}, \mathrm{mg} \mathrm{C}\right)$ and oozoid $\left(O_{R}, \mathrm{mg} C\right)$ reproductive energy. Abundance and biomass (size) are tracked throughout the model to be consistent with observations. Temperature and chlorophyll $a$ (a proxy for food abundance) have been shown to be important drivers of salp population dynamics (Heron, 1972; Deibel, 1982; Perissinotto and Pakhomov, 1998b; Kawaguchi et al., 2004; Henschke et al., 2014), and are included here as external drivers affecting growth, consumption, reproduction and mortality rates (Fig. 2).

\subsubsection{Salp abundance}

The change of abundance of female blastozooids $\left(F_{N}\right.$; ind. $\left.\mathrm{m}^{-3}\right)$ in

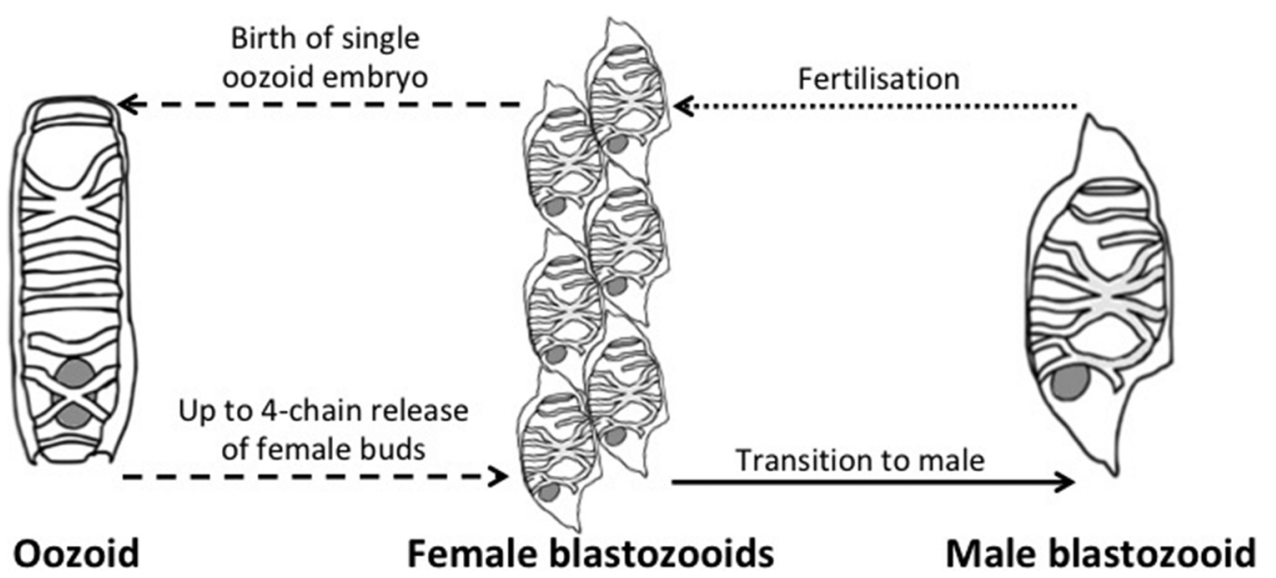

Fig. 1. Salpa thompsoni life cycle. The typical salp life cycle involves the obligatory alternation between two life stages: the sexually reproducing blastozooids, and the asexually reproducing oozoids. In the blastozooid generation, the young blastozooid buds are female and are immediately fertilised upon release by older male blastozooids. These females grow a single internal embryo, which is the beginning of the oozoid generation. After releasing the oozoid embryo, the female blastozooids develop testes and function as male. The oozoid embryo grows to asexually produce up to four releases of genetically identical blastozooid buds. Dashed lines represent change of generation, the solid line represents growth and the dotted line represents external fertilisation. 


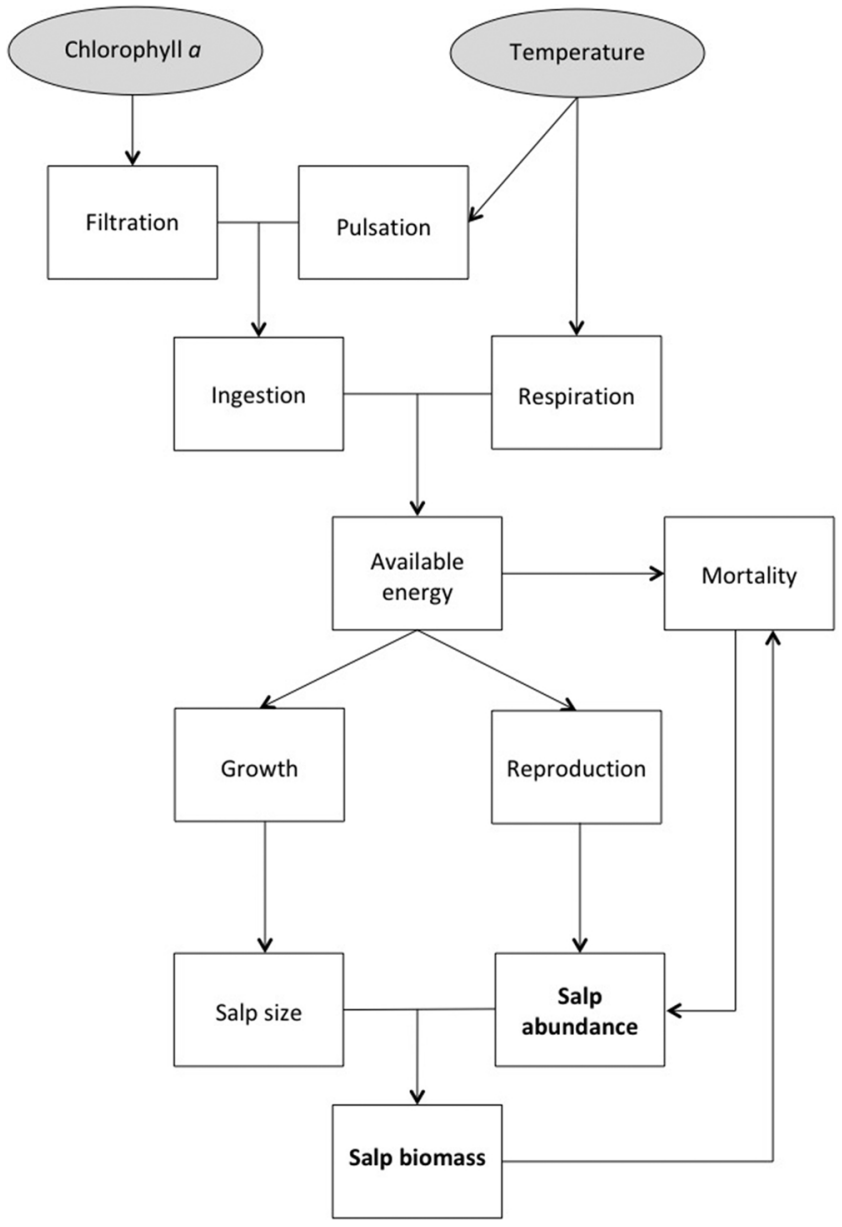

Fig. 2. Model schematic for the Salpa thompsoni population model. External drivers are represented by the grey ovals.

each cohort is given by:

$\frac{d F_{N}}{d t}=$ buds - mort $\cdot F_{N}-$ starve $\cdot F_{N}-\operatorname{repro} \cdot F_{N}$

where buds (see Eq. (17)) is the number of female blastozooids released from reproducing oozoids per day (ind. $\mathrm{m}^{-3} \mathrm{~d}^{-1}$ ), mort (natural; $\mathrm{d}^{-1}$ ) and starve (starvation; $\mathrm{d}^{-1}$ ) are mortality rates, and repro is the transition rate of female blastozooids to male blastozooids $\left(\mathrm{d}^{-1}\right)$. The contribution of buds only occurs when oozoids are reproductive, and the transition rate of reproducing females (repro) to males only occurs when females reach reproductive size; both are not continuous throughout time.

Once females release an oozoid embryo (embryo), they develop testes and transition into males:

$\frac{d M_{N}}{d t}=\operatorname{repro} \cdot F_{N}-\operatorname{mort} \cdot M_{N}-$ starve $\cdot M_{N}$

The change in male blastozooids $\left(M_{N}\right.$; ind. $\left.\mathrm{m}^{-3}\right)$ in each cohort is dependent on the amount transitioning from females (repro $F_{N}$; ind. $\mathrm{m}^{-3} \mathrm{~d}^{-1}$ ) less those lost from natural (mort; $\mathrm{d}^{-1}$ ) and starvation (starve; $\mathrm{d}^{-}$ $\left.{ }^{1}\right)$ mortality.

The release of the oozoid embryo (embryo; Eq. (15)) is the start of the next generation. The change in oozoid abundance $\left(O_{N}\right.$; ind. $\left.\mathrm{m}^{-3}\right)$ in each cohort is dependent on the amount of embryos released per day (ind. $\mathrm{m}^{-3} \mathrm{~d}^{-1}$ ) less mortality (mort, starve; $\mathrm{d}^{-1}$ ):

$\frac{d O_{N}}{d t}=$ embryo-mort $\bullet O_{N}-$ starve $\bullet O_{N}$

The contribution of embryo only occurs when blastozooids are reproducing and is not continuous through time.

\subsubsection{Mortality}

There are no known estimates for mortality rates of Salpa thompsoni. Here we assume two sources of mortality, a density-dependent natural mortality that includes predation pressure and a starvation mortality. The only empirical, laboratory-based measurement for salp mortality is $\sim 10 \% \mathrm{~d}^{-1}$ for populations of the small salp Thalia democratica (size range $<1-15 \mathrm{~mm}$; Deibel, 1982), which has been converted to a length-based mortality curve for previous salp population models (Henschke et al., 2015). Extending the mortality rate curve for the size range of $S$. thompsoni $(4-150 \mathrm{~mm})$, here we use a population mortality rate of $1 \% \mathrm{~d}^{-1}$. This mortality is scaled such that mortality reaches $5 \% \mathrm{~d}^{-}$ ${ }^{1}$ under high salp densities:

mort $=\left(m \cdot \sum S_{C}{ }^{2}\right)$

where $S_{C}$ is the carbon biomass of the salp population $\left(\mathrm{mg} \mathrm{C} \mathrm{m}^{-3}\right)$. As size and abundance are tracked for each individual throughout the model, the population biomass $\left(S_{C}\right)$ can be determined at each time step. $m$ is the mortality rate such that mortality is $1 \% \mathrm{~d}^{-1}$ at low densities $\left(S_{C}=0.577 \mathrm{mg} \mathrm{C} \mathrm{m}^{-3}\right)$ and reaches $5 \% \mathrm{~d}^{-1}$ at high densities $\left(S_{C}\right.$ $=1.291 \mathrm{mg} \mathrm{C} \mathrm{m}^{-3}$; Table 1 ). Similar density-dependent mortality rates have been assumed for other gelatinous zooplankton (Oviatt and Kremer, 1977; Henschke et al., 2018) and mesozooplankton (Ohman et al., 2002) based on the assumption that the biomass of unresolved predators scales in proportion to the biomass of unresolved prey (Steele and Henderson, 1993).

Starvation occurs when respiratory needs exceed available food for consumption (i.e. when resp > cons; see Section 2.1.3). Here we assume that a Salpa thompsoni population can withstand approximately 100 days without food prior to $100 \%$ mortality. This assumption is based on mortality rates for similar sized polar zooplankton (Lee et al., 2006) as there is no empirical data for $S$. thompsoni starvation rates. Thus starvation mortality starve $\left(\mathrm{d}^{-1}\right)$ is:

starve $=0.05$ if resp $>$ cons

Another potential form of starvation mortality is believed to occur under high phytoplankton concentrations when salp feeding efficiency is reduced ( $>1.5 \mathrm{mg} \mathrm{m}^{-3}$; Perissinotto and Pakhomov, 1998a). However, it is unclear if clogging regularly occurs under high phytoplankton concentrations, occurs because of sustained periods of high concentrations, or due to high densities of a particular phytoplankton species. Additionally, in experimental conditions, Salpa thompsoni has been observed "backwashing", similar to the small salp Thalia democratica, which is a behaviour that can clear a clogged feeding apparatus (Deibel, 1985). Due to this large uncertainty, we have not included clogging as a method of mortality in this model. Nonetheless, chlorophyll $a$ concentrations in this model did not exceed $1.5 \mathrm{mg} \mathrm{m}^{-3}$, hence, clogging mortality would not have occurred.

\subsubsection{Consumption}

Salp consumption ( $\mathrm{mg} \mathrm{C} \mathrm{d}^{-1}$ ) is given by:

Cons $=$ Ing-Resp

where Ing is the ingestion rate, and Resp is the respiration rate. This is representative across all life stages. Salp consumption rate determines the amount of energy that is available to be allocated towards growth and reproduction.

Salpa thompsoni ingestion rate $\left(\mathrm{mg} \mathrm{C} \mathrm{d}^{-1}\right)$ in this model is size and temperature dependent. Salps are highly efficient filter feeders (Henschke et al., 2016), and empirical evidence has suggested that $S$. thompsoni filtration rates vary with size and generation (von Harbou, 2009). As salps feed continuously while swimming, ingestion is therefore further limited by their pulsation rate. Salp ingestion of available chlorophyll $a$ biomass is: 
Table 1

Parameter values used in the model simulation.

\begin{tabular}{|c|c|c|c|c|c|}
\hline Parameter & Equation & Definition & Value & Units & Source \\
\hline$m$ & (4) & Mortality rate parameter & 0.03 & $\left(\mathrm{mg} \mathrm{C} \mathrm{m}{ }^{-3}\right)^{-2} \mathrm{~d}^{-1}$ & Best guess \\
\hline$\gamma$ & (6) & Assimilation efficiency & $0.64^{*}$ & & Iguchi and Ikeda (2004) \\
\hline$a, b$ & (8) & Blastozooid filtration rate & $1.1098,0.031$ & $\mathrm{mg} \mathrm{Cmg} \mathrm{C} \mathrm{m}^{-1} \mathrm{~d}^{-1}, \mathrm{mg} \mathrm{C}^{-1}$ & von Harbou (2009) \\
\hline$a, b$ & (8) & Oozoid filtration rate & $1.3463,0.009$ & $\mathrm{mgCmg} \mathrm{C}^{-1} \mathrm{~d}^{-1}, \mathrm{mg} \mathrm{C}^{-1}$ & von Harbou (2009) \\
\hline$c, d, f$ & (9) & Pulsation rate parameters & $-0.0092,0.0832,0.8055^{*}$ & ${ }^{\circ} \mathrm{C}^{-2},{ }^{\circ} \mathrm{C}^{-1}$ & Henschke and Pakhomov (in review) \\
\hline$g, h$ & (10) & Respiration rate parameters & $1.1268,0.931^{*}$ & $d^{-1}$ & Iguchi and Ikeda (2004) \\
\hline$j, k$ & (11) & Respiration rate temperature correction multiplier & $0.766^{\prime \prime}, 0.18$ & ${ }^{\circ} \mathrm{C}^{-1}$ & Iguchi and Ikeda (2004) \\
\hline$n, o$ & (13) & Carbon weight to length relationship & $17.324,0.4292^{*}$ & $\mathrm{~mm} \mathrm{mg}^{-1}$ & (Huntley et al., 1989) \\
\hline$p, q$ & (16) & Embryo mortality parameters & $-0.033,0.7083^{*}$ & ${ }^{\circ} \mathrm{C}^{-1} \mathrm{~d}^{-1}$ & Henschke and Pakhomov (in review) \\
\hline$r, s$ & (18) & H1 maximum growth rate & $0.0237,-0.429^{*}$ & $\% d^{-1}$ & Loeb and Santora (2012) \\
\hline$t, u$ & (19) & H2 maximum growth rate & $0.0427,-0.207^{*}$ & $\% \mathrm{~d}^{-1}$ & Pakhomov and Hunt (2017) \\
\hline
\end{tabular}

* Indicates dimensionless parameters. H1 is Hypothesis 1, H2 is Hypothesis 2.

Ing $=\gamma \cdot$ Filt $\bullet F_{C} \cdot P R$

where $\gamma$ is the assimilation efficiency (dimensionless), $F_{c}$ is the size of a female individual (mg C), $P R$ is the proportional temperature dependent pulsation rate (dimensionless), and Filt is the size dependent filtration rate $\left(\mathrm{mg} \mathrm{C} \mathrm{mg} \mathrm{C}^{-1} \mathrm{~d}^{-1}\right)$ such that:

Filt $=a \cdot e^{\left(-b \cdot F_{C}\right)}$

where $a$ and $b$ are parameters that vary depending on generation (see Table 1).

Pulsation rate (i.e. swimming speed) in salps have been shown to be temperature dependent (Harbison and Campenot, 1979). While there exists no data on pulsation rates for Salpa thompsoni here we assume that maximum pulsation will occur at temperatures between $4-5{ }^{\circ} \mathrm{C}$ and decline on either side of this "optimal" temperature. This is based on observations that have identified that $S$. thompsoni perform better, and occur in higher densities in warmer waters of the Antarctic Polar Front compared to high latitude areas (eg. Casareto and Nemoto, 1986; Chiba et al., 1999; Pakhomov and Froneman, 2004).

Pulsation rates for Salpa spp. are reduced to $\sim 60 \%$ of maximum when temperatures are reduced to the minimum experienced locally (Harbison and Campenot, 1979). As S. thompsoni has been observed actively swimming in water under the sea ice $\left(<0{ }^{\circ} \mathrm{C}\right.$; Pakhomov, pers. obs.) here we assume that pulsation rate reduces to $60 \%$ at very low temperatures $\left(-2^{\circ} \mathrm{C}\right)$. Pulsation rate (dimensionless) is proportional and is calculated as the difference between the current temperature and that at which maximum pulsation rate occurs $\left(4.5^{\circ} \mathrm{C}\right)$ :

$P R=c \cdot T^{2}+d \cdot T+f$

where $T$ is temperature $\left({ }^{\circ} \mathrm{C}\right.$ ); $c, d$ and $f$ are parameters (see Table 1 ).

\subsubsection{Respiration}

Respiratory costs (mg C d ${ }^{-1}$ ) are calculated based on the empirical relationship in (Iguchi and Ikeda, 2004):

$\operatorname{Resp}_{F}=T_{C} \cdot g \cdot F_{C}{ }^{h}$

where $T_{C}$ is the temperature correction multiplier (dimensionless), $F_{C}$ is female size (mg C), $g$ and $h$ are parameters (see Table 1). As Salpa thompsoni respiration rates were calculated at $1.3^{\circ} \mathrm{C}$, and given a $\mathrm{Q}_{10}$ of 2.8 (Iguchi and Ikeda, 2004), $T_{C}$ scales respiration rates appropriately for varying temperature (T) such that $T_{C}=1$ at $1.3{ }^{\circ} \mathrm{C}$ and $T_{C}=2.8$ at $11.3^{\circ} \mathrm{C}$

$T_{C}=j+k \cdot T$

where $j$ and $k$ are parameters (see Table 1).

\subsubsection{Growth and reproduction}

The growth of salps ( $\mathrm{mg} \mathrm{C} \mathrm{d}^{-1}$ ) in each cohort is given by:

$\frac{d F_{C}}{d t}=$ Cons-Repro where Cons is consumption (mg C d $\mathrm{d}^{-1}$ ) and Repro is the amount of energy partitioned to reproduction $\left(\mathrm{mg} \mathrm{C} \mathrm{d}^{-1}\right)$. This is representative for females $\left(\right.$ Repro $\left._{F}\right)$ and oozoids $\left(\right.$ Repro $\left._{O}\right)$; there are no reproductive costs for males. Salp size (mg C) can be converted to length $\left(F_{L} ; \mathrm{mm}\right)$ using the empirical relationship derived by Huntley et al. (1989):

$F_{L}=n \cdot F_{C}{ }^{o}$

where $n$ and $o$ are parameters (see Table 1).

The amount of energy partitioned to reproduction is stored by individual females $\left(F_{R} ; \mathrm{mg} \mathrm{C}\right)$ and oozoids $\left(O_{R} ; \mathrm{mg} \mathrm{C}\right)$ in each cohort until they are of reproductive size:

$\frac{d F_{R}}{d t}=\sum$ Repro $_{F} \quad$ and $\quad \frac{d O_{R}}{d t}=\sum$ Repro $_{O}$

The cohort repro $\cdot F_{N}$ of females that are large enough to reproduce $(25 \mathrm{~mm} ; 2.3 \mathrm{mg} \mathrm{C})$ and have enough reproductive energy stored $\left(F_{R} \geq 0.0329 \mathrm{mg} C\right)$ will release a $4 \mathrm{~mm}(0.0329 \mathrm{mg} \mathrm{C})$ oozoid embryo (Foxton, 1966) and begin to function as males. Given an embryo mortality mort $_{E}$ the number of alive embryos (ind. $\mathrm{m}^{-3} \mathrm{~d}^{-1}$ ) for a given time interval ( $\Delta \mathrm{t}=1$ day) is given by:

embryo $=\operatorname{repro} \bullet F_{N} \cdot \operatorname{mort}_{E} \cdot \Delta t$

Higher proportions of embryos that have failed to develop properly have been observed in low temperatures (Henschke and Pakhomov, in review). Thus, here we assume embryo mortality rate is temperature dependent, and is applied directly after embryo release:

$\operatorname{mort}_{E}=p \cdot T+q$

where $\operatorname{mort}_{E}$ is the embryo mortality rate $\left(\mathrm{d}^{-1}\right), p$ and $q$ are parameters (see Table 1). As embryo release has been observed to occur in March/ April (Foxton, 1966), release times were limited to the 2 month period after the annual maximum temperature, which generally occurs in late February, if females were of reproductive size.

Oozoids will release a maximum of 4 chains of 170-250 buds between approximately $65 \mathrm{~mm}(22 \mathrm{mg} \mathrm{C})$ and $90 \mathrm{~mm}(50 \mathrm{mg} \mathrm{C})$, with total release of all 4 chains generally occurring within a month (Foxton, 1966; Daponte et al., 2001). The number of buds released (ind. $\mathrm{m}^{-3}$ $\left.\mathrm{d}^{-1}\right)$ is dependent on oozoid size $\left(O_{C}\right)$ and the amount of reproductive energy stored $\left(O_{R}\right)$ :

buds $=\frac{O_{N}}{\Delta t} \cdot \frac{O_{R}}{0.0329} \quad$ if $O_{R} \geq 5.5971 \mathrm{mg} C, O_{C} \geq 22 \mathrm{mgC}$

where $\frac{O_{N}}{\Delta t}$ is the amount of reproducing oozoids (ind. $\mathrm{m}^{-3}$ ) for a given time interval ( $\Delta \mathrm{t}=1$ day), 0.0329 is the amount of energy required to create one blastozooid bud (mg C) and 5.5971 is the amount of energy required to create 170 buds. Since reproduction has not been observed to occur in winter (Foxton, 1966; Ross and Quetin, 1996) it suggests a seasonal limitation on reproduction. As a first approximation, here we assume that reproduction can only occur in summer months, when temperature is greater than the median annual temperature, and that budding is limited to occur within a month of first chain release. 
Although several studies have observed seasonal dynamics in Salpa thompsoni bloom formation, the factors driving when reproduction occurs are unknown. Since the seasonal limitations on reproduction are estimates, they need to be tested in relevant sensitivity analyses. Observations suggest that biomass of salps is higher in summer months and near zero during winter (Foxton, 1966). Yet, removing the seasonal limitation results in multiple reproductive events occurring within a year, and does not recreate the observed seasonal abundances ( $p>0.05$; Fig. S1), suggesting that synchronous reproduction is necessary to recreate observed seasonal dynamics.

\subsubsection{Growth hypotheses}

There is uncertainty around Salpa thompsoni growth rates, and it is unknown how much energy is partitioned between growth and reproduction. Here we run a suite of hypothesis tests as described below to explore potential partitioning and growth rate relationships:

Hypothesis 1. Slow growth. Here we assume growth rates range between $0.23-0.41 \mathrm{~mm}$ body length $\mathrm{d}^{-1}$ as in Loeb and Santora (2012). The remainder of energy not partitioned to growth will go to reproduction. These growth rates have been observed at the Antarctic Peninsula $\left(\sim 61^{\circ} \mathrm{S}\right)$ and can be represented by the power curve:

Growth $_{H 1}=r \cdot \mathrm{F}_{C}{ }^{s}$

where Growth $_{H 1}$ is maximum growth in \% body $\mathrm{C} \mathrm{d}^{-1}, r$ and $s$ are parameters (see Table 1).

Hypothesis 2. Fast growth. Here we assume growth rates range between $0.53-2.83 \mathrm{~mm}$ body length $\mathrm{d}^{-1}$ as in Pakhomov and Hunt (2017). The remainder of energy not partitioned to growth will go to reproduction. This has been observed at the Antarctic Polar Front $\left(\sim 50^{\circ} \mathrm{S}\right)$ and can be represented by the power curve:

Growth $_{H 2}=t \cdot \mathrm{F}_{C}{ }^{u}$

where Growth $_{\mathrm{H} 2}$ is maximum growth in \% body $\mathrm{C} \mathrm{d}^{-1}, t$ and $u$ are parameters (see Table 1).

Hypothesis 3. Proportional growth. Here we assume that the amount of energy partitioned between growth and reproduction will be proportional to the ratio of adult size to offspring size. On the assumption that a $25 \mathrm{~mm}(2.3 \mathrm{mg} \mathrm{C})$ female will release a $4 \mathrm{~mm}$ $(0.0329 \mathrm{mg} \mathrm{C})$ embryo, their lifetime reproductive output is $0.0329 \mathrm{mg} \mathrm{C}$; a 99:1 ratio between growth and reproduction (i.e. $\frac{d F_{C}}{d t}=0.99 \cdot$ Cons $_{F}, \frac{d F_{R}}{d t}=0.01 \cdot$ Repro $_{F}$ ). Oozoid lifetime reproductive output is $\sim 19 \mathrm{mg} \mathrm{C}$ ( 3 chains of 190 buds), equating to a ratio of $\sim 70: 30$ between growth and reproduction for the first chain (released at parent size of $22 \mathrm{mg} \mathrm{C}$ ), with reproduction increasing to release the next three chains to a ratio of $37: 63$ by parent size of $50 \mathrm{mg}$ C. The benefit of the proportional growth hypothesis is that if food is limiting, energy will still be partitioned between growth and reproduction, whereas in Hypotheses 1 and 2, growth will be preferred over reproduction.

\subsection{Model simulation}

The model was forced with temperature from NOAA version 2 optimally interpolated daily high-resolution-blended sea surface temperature estimates with $1^{\circ}$ spatial resolution (OISST.v2; Reynolds et al., 2007). These estimates include a combination of measurements from infrared (AVHRR) satellite sensors and in-situ bucket, buoy and shipbased observations. Chlorophyll $a$ biomass was used as a proxy of phytoplankton available for salp consumption in the model. Chlorophyll $a$ biomass was obtained from sea-viewing wide field-of-view sensor (SeaWiFS) chlorophyll $a$ concentration (OC4 algorithm) with a $9 \mathrm{~km}$ and 1 month resolution (NASA, 2015). We derived $1^{\circ}$ spatially resolved data using natural neighbor interpolation (Matlab function: scatteredInterpolant). To reduce bias due to cloud cover, pixels with no data were assumed to equal averages of surrounding pixels, or given a low chlorophyll $a$ value if during the austral winter (chl $a=0.05 \mathrm{mg} \mathrm{C}$ $\mathrm{m}^{-3}$ ). Satellite data spanned from 1997-2009. The model is run in an idealized $1 \mathrm{~m}^{2} \times 400 \mathrm{~m}$ box to represent the mean depth range of a migrating Salpa thompsoni. This model does not consider diel vertical migration. Since the time-step of our model is 1 day, we can assume that over this time period salps were evenly distributed over $400 \mathrm{~m}$. Sea surface temperature and chlorophyll $a$ values for each model location were consistent with studies of growth rate estimates; the Antarctic Polar Front $\left(50.5^{\circ} \mathrm{S}, 12.5^{\circ} \mathrm{W}\right.$; Pakhomov and Hunt, 2017) and the Antarctic Peninsula $\left(61.5^{\circ} \mathrm{S}, 51.5^{\circ} \mathrm{W}\right.$; Loeb and Santora, 2012). The initial abundances of females was set at 1 ind. $\mathrm{m}^{-3}$, zero males and zero oozoids in order to have only one reproductive generation existing initially. The model was spun up for 100 years with climatological (1997-2009) mean values until it reached steady state before simulating the different growth and environmental scenarios. To test seasonal abundance/biomass patterns, the model was run with climatological mean values; to explore interannual variation the model was run for the duration of the Loeb and Santora (2012) sampling period where satellite data was available (1997-2009). Salp observations for comparison were obtained from KRILLBASE and Loeb and Santora (2012). KRILLBASE is a freely available database containing $S$. thompsoni numerical densities in the Southern Ocean, spanning from 1926 to 2016 (Atkinson et al., 2017). Biomass index (i.e. standardized biomass; $\mu=0, \sigma=1)$ was used to compare modelled $\left(\mathrm{mg} \mathrm{C} \mathrm{m}^{-3}\right)$ and observed biomass (mg C m${ }^{-2}$ ) due to differences in metrics. Parameter uncertainty was assessed with a Monte-Carlo approach, where each of the parameters in Table 1 were randomly varied by $\pm 20 \%$ of their value until their variance stabilized (1000 model realizations). Statistical linear modelling was undertaken to explore the demographic and environmental drivers of modelled salp biomass. Demographic covariates that were included in the linear model were time of budding, time of embryo release, growth rate, starvation mortality, amount of buds released and the amount of embryos released. To test for the effects of environmental drivers, seasonal temperature and chlorophyll $a$ concentrations were included as covariates in the linear model.

\section{Results}

This model simulated the seasonal dynamics of Salpa thompsoni in two locations, the Antarctic Polar Front and the Antarctic Peninsula, given the appropriate growth rate hypothesis (Fig. 3). No salps survived the initial model spin-up when run under Hypothesis 1, the slow growth scenario. Simulations under Hypothesis 2 (the fast growth scenario) and Hypothesis 3 (the proportional growth scenario) were able to reproduce the observed KRILLBASE seasonal dynamics in $S$. thompsoni abundance at both locations with salps more abundant during the austral summer (December-February) compared to other seasons (Table 2; Fig. 3). Modelled salps were more abundant under the Hypothesis 2 simulation compared to Hypothesis 3, and for both simulations were more abundant in the high Antarctic location. Mean growth rates were faster in the Hypothesis 3 scenario, but were of similar magnitude to Hypothesis 2 (Fig. 4). Interannual variability of austral summer salp biomass was only captured by the Hypothesis 3 simulation $(r=0.84, p<0$. 01 ; Fig. 5). These trends were robust to uncertainty in parameters other than growth rates (Fig. S2).

As Hypothesis 3 reproduced the most realistic salp bloom dynamics, we now analyze this simulation to gain insight into factors capable of explaining observed variations in salp bloom dynamics in the Southern Ocean. Abundances varied from 0.01 to 0.31 individuals (ind.) $\mathrm{m}^{-3}$, with a blastozooid-to-oozoid ratio ranging from 1.16 during the winter to highs of 855.69 in summer (Table 3). Embryo release generally occurred in March and bud release occurred in November. Varying release times by \pm 1 month showed little variation in seasonal trends in salp biomass (Fig. S2). On average 4 chains of buds totaling 842 individuals were released per oozoid (Table 3). Generation times (birth until 

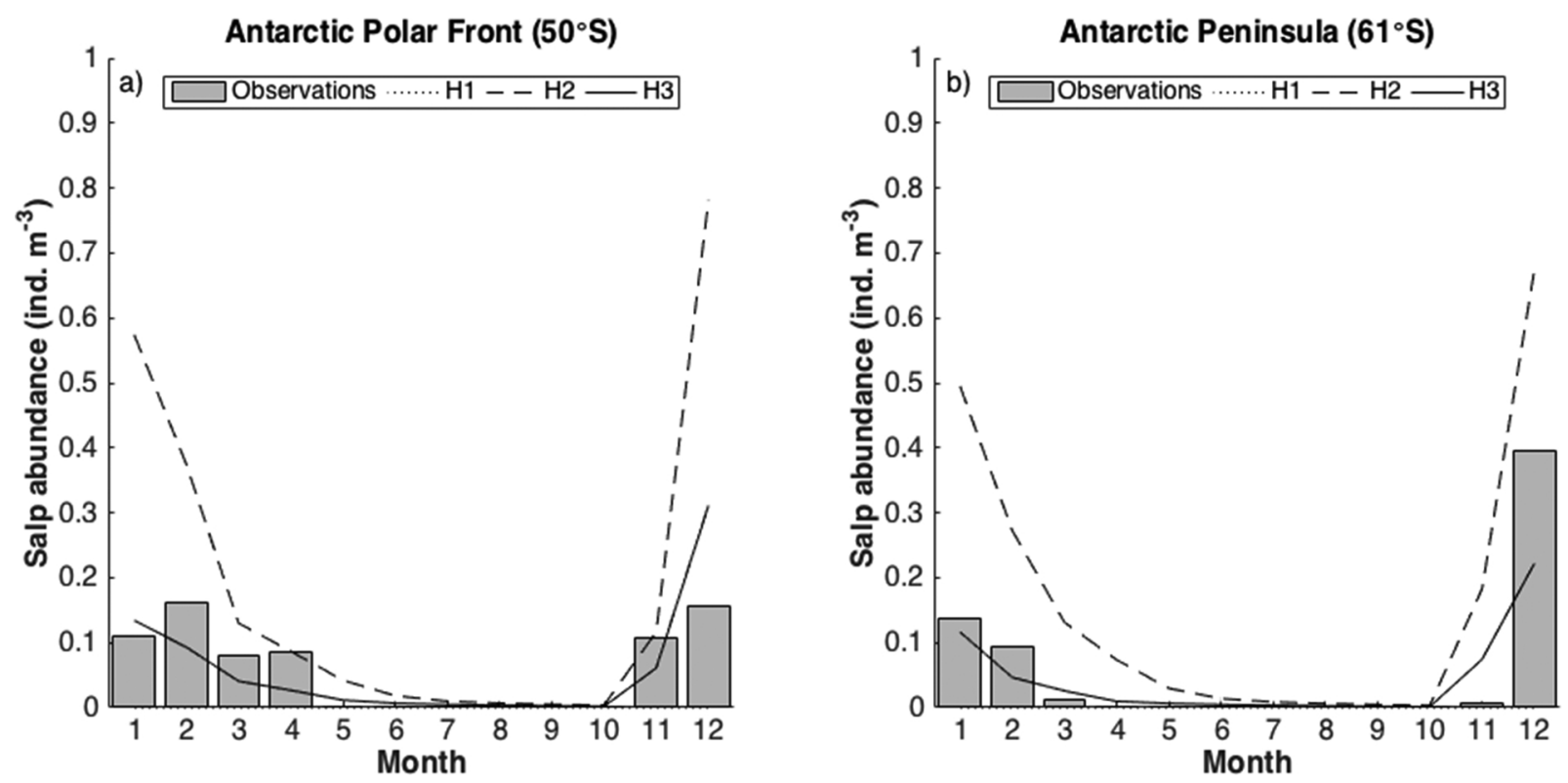

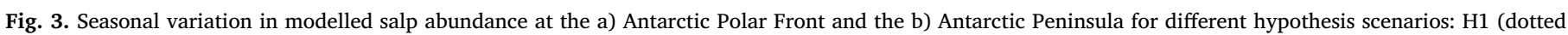

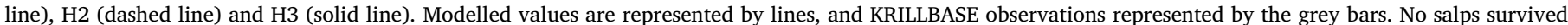
after model spin-up in the $\mathrm{H} 1$ scenario.

Table 2

Pearson correlation results for monthly $S$. thompsoni biomass simulated at the Antarctic Polar Front and the Antarctic Peninsula for each hypothesis scenario.

\begin{tabular}{|c|c|c|c|c|}
\hline & \multicolumn{2}{|c|}{ Antarctic Polar Front } & \multicolumn{2}{|c|}{ Antarctic Peninsula } \\
\hline & $\mathrm{R}$ & $p$ value & $\mathrm{R}$ & $p$ value \\
\hline Hypothesis 1 & - & - & - & - \\
\hline Hypothesis 2 & 0.81 & 0.0014 & 0.93 & $<0.0001$ \\
\hline Hypothesis 3 & 0.77 & 0.0035 & 0.95 & $<0.0001$ \\
\hline
\end{tabular}

reproduction) were 267 days for oozoids and 98 days for blastozooids making a complete life cycle in 365 days. Without seasonal limitations on reproduction however, reproduction may occur continuously throughout the year, with generation times as fast as 80 days for oozoids and 27 days for blastozooids (Fig. S1). Annual mean growth rate was $0.75-1.05 \mathrm{~mm} \mathrm{~d}^{-1}$, and varied seasonally, from $0.02 \mathrm{~mm} \mathrm{~d}^{-1}$ in the austral autumn to $2.08 \mathrm{~mm} \mathrm{~d}^{-1}$ in spring (Table 3 ).

When run under various environmental scenarios: high temperature, high chlorophyll $a$ (HTHC), high temperature, low chlorophyll $a$ (HTLC), low temperature, high chlorophyll $a$ (LTHC) and low temperature, low chlorophyll $a$ (LTLC), significantly larger populations of $S$. thompsoni occurred during the HTLC conditions $(\mathrm{p}<0.001$, $\mathrm{F}_{3,76}=287.76$; Fig. 6).

Linear modelling identified that the most important demographic driver of interannual variations in salp biomass was the time of budding (i.e. release day of the first chain of buds) with higher biomass occurring when oozoids are released buds later in the year $\left(r^{2}=0.65\right.$, $\mathrm{p}<0.001, \mathrm{~F}_{1,10}=21.31$ ). Later bud release times were also significantly correlated with increased abundances of released embryos in the following summer $(r=0.8, p<0.01)$. Environmental drivers of interannual salp biomass were spring and summer chlorophyll $a$ concentrations, and summer temperature $\left(\mathrm{r}^{2}=0.62, \mathrm{p}=0.03\right.$, $\mathrm{F}_{4,7}=5.449$; Table 4). Less productive springs and cooler and more productive summers resulted in higher salp biomass. Less productive springs resulted in lower mortality rates for large oozoids in springearly summer (density dependent mortality; $r=0.85$, $p<0.01$ ), increasing bud release and allowing more blastozooids to rapidly grow and survive in productive summer conditions until embryo release.
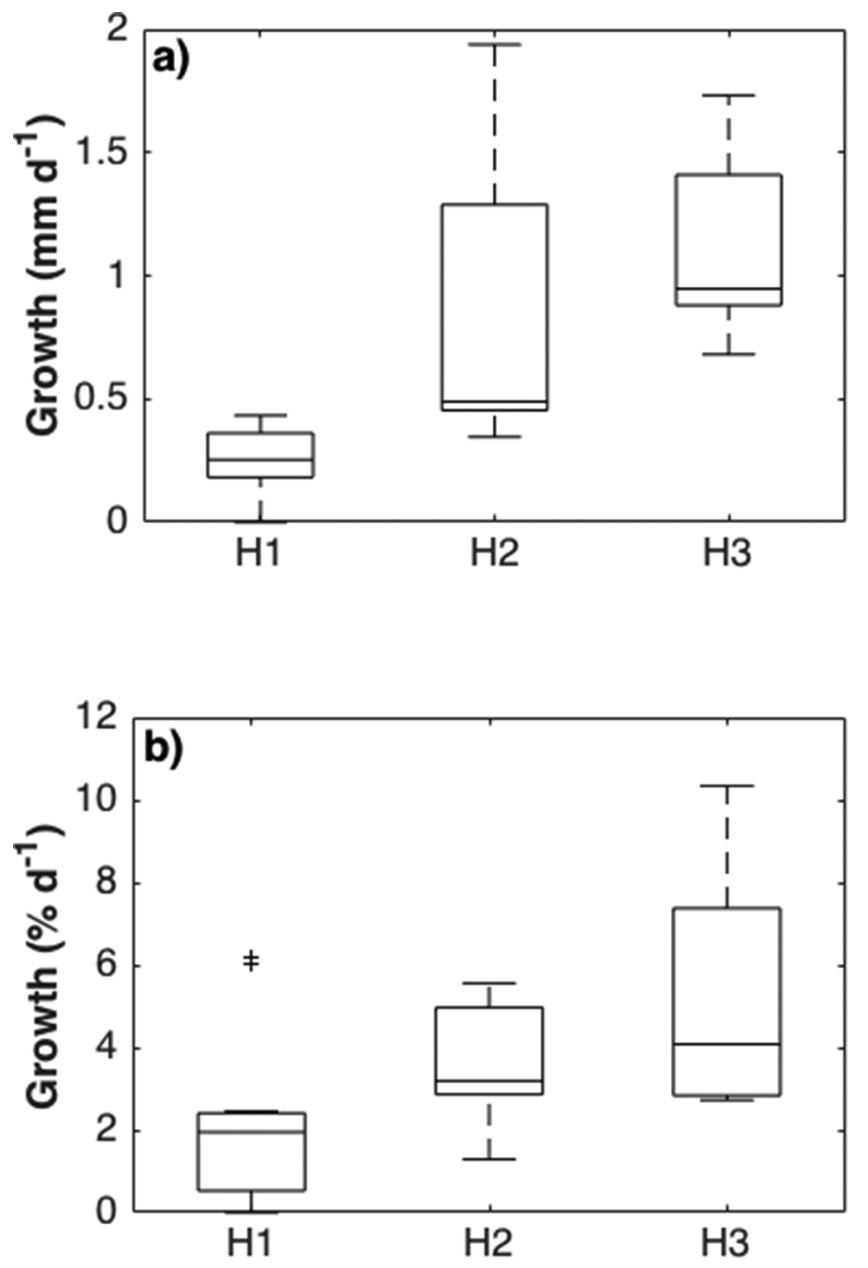

Fig. 4. Mean growth rate in a) mm body length $d^{-1}$ and b) $\%$ body size $d^{-1}$ across three hypothesis scenarios. The central line of each box indicates the median, the edges indicate the 25th and 75th percentiles and the whiskers extend to the most extreme data points. Outliers are plotted using the + symbol. 


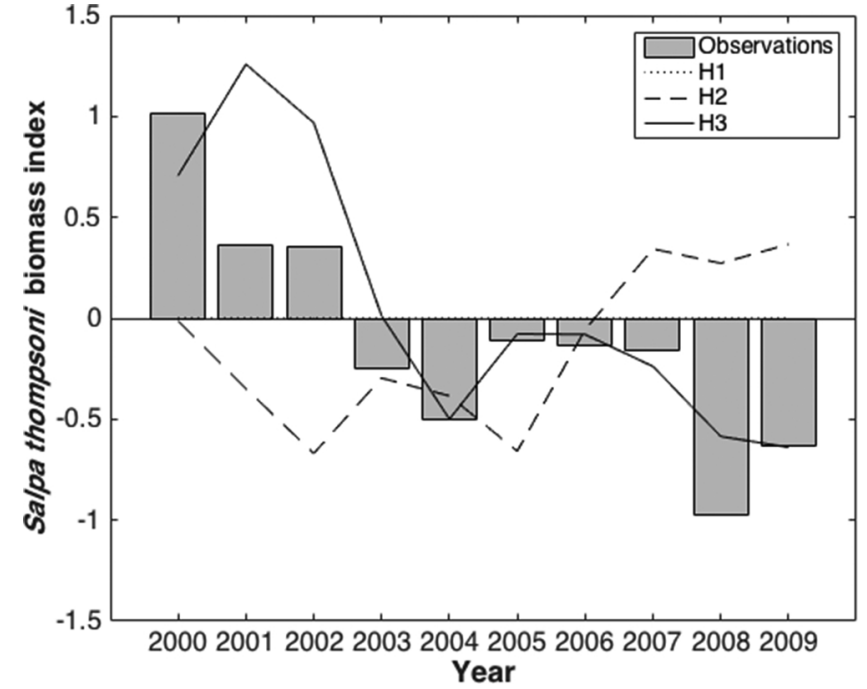

Fig. 5. Interannual variation (3-yr running mean) in biomass index (standardized salp biomass; $\mu=0, \sigma=1$ ) in the Antarctic Peninsula. Observations from Loeb and Santora (2012) are represented by grey bars, H1 model output is represented by the dotted line, $\mathrm{H} 2$ model output is represented by the dashed line, and $\mathrm{H} 3$ represented by the solid line.

\section{Discussion}

This is the first size-structured population model for the Southern Ocean salp, Salpa thompsoni, and incorporates both blastozooid and oozoid life stages with temperature and chlorophyll $a$ dependent growth, reproduction and mortality rates. It is challenging to fully explore the dynamics of $S$. thompsoni life cycles using observations alone due to how difficult salps are to sample and culture in the laboratory (Raskoff et al., 2003). They are fragile, best collected by diving, and can be hard to find due to the patchy and ephemeral nature of their swarms (Henschke et al., 2016). Additionally, as Southern Ocean sampling is generally restricted to summer months there are limitations to how much seasonal analysis on salp abundance can be performed, so in several locations there is a lack of winter observations of $S$. thompsoni. In combination with observations, population modelling allows us to explore factors that drive $S$. thompsoni population dynamics, better understand the environmental conditions that result in blooms and interpolate between sparse datasets. Temperature and chlorophyll $a$ were sufficient drivers to create realistic seasonal and interannual population dynamics of $S$. thompsoni. The proportional growth rate hypothesis (H3) was the most appropriate growth rate scenario to recreate the observed patterns in $S$. thompsoni populations. The time of budding strongly influences the magnitude of the $S$. thompsoni population, with large salp years occurring when there was increased survival of older oozoids, and favorable summer conditions during and following embryo release. This is consistent with a previous salp model that was developed for Salpa fusiformis which identified that reproduction rate was the most important factor influencing population abundance (Andersen and Nival, 1986).

\subsection{Salpa thompsoni growth rate}

As there was significant uncertainty surrounding Salpa thompsoni growth rates, we performed a suite of hypothesis tests to identify the most appropriate growth rate relationship. Growth rates in H1, the slow growth scenario, were too slow to recreate a $S$. thompsoni population. The fast growth rate scenario (H2) and the proportional growth scenario (H3) were able to recreate the seasonal dynamics of the $S$. thompsoni population, suggesting that mean growth rates for $S$. thompsoni are higher than the $0.41 \mathrm{~mm}$ body length $\mathrm{d}^{-1}$ Loeb and Santora (2012) estimated. H3 was the only scenario able to recreate interannual variation observed in $S$. thompsoni biomass, and generally resulted in higher growth rates than $\mathrm{H} 2$. This suggests that the growth rate

Table 3

Mean ( \pm SD) demographic characteristics for modelled salp swarms under the Hypothesis 3 growth scenario.

\begin{tabular}{|c|c|c|c|c|c|c|}
\hline & & Abundance (ind. $\mathrm{m}^{-3}$ ) & Biomass ( $\mathrm{mg} \mathrm{C} \mathrm{m}^{-3}$ ) & $\begin{array}{l}\text { Growth rate (mm } \\
\mathrm{d}^{-1} \text { ) }\end{array}$ & $\begin{array}{l}\text { Blastozooid-to-oozoid } \\
\text { ratio }\end{array}$ & $\begin{array}{l}\text { Asexual reproduction (buds } \\
\text { oozoid }^{-1} \text { ) }\end{array}$ \\
\hline \multirow[t]{5}{*}{ H3 - Antarctic Polar Front } & Annual & $0.08 \pm 0.15$ & $0.58 \pm 0.26$ & $1.05 \pm 0.74$ & $222.44 \pm 382.75$ & 842 \\
\hline & Spring (SON) & $0.03 \pm 0.05$ & $0.27 \pm 0.07$ & $0.71 \pm 1.22$ & $31.65 \pm 52.82$ & - \\
\hline & $\begin{array}{l}\text { Summer } \\
\text { (DJF) }\end{array}$ & $0.24 \pm 0.19$ & $0.83 \pm 0.28$ & $0.72 \pm 0.98$ & $855.69 \pm 0.002$ & - \\
\hline & $\begin{array}{l}\text { Autumn } \\
\text { (MAM) }\end{array}$ & $0.03 \pm 0.01$ & $0.63 \pm 0.14$ & $1.3 \pm 0.47$ & $1.26 \pm 0.18$ & - \\
\hline & Winter (JJA) & $0.01 \pm 0.003$ & $0.59 \pm 0.1$ & $0.43 \pm 0.38$ & $1.16 \pm<0.001$ & - \\
\hline \multirow[t]{5}{*}{ H3 - Antarctic Peninsula } & Annual & $0.12 \pm 0.25$ & $0.44 \pm 0.33$ & $0.75 \pm 0.94$ & $157.79 \pm 329.59$ & 842 \\
\hline & Spring (SON) & $0.1 \pm 0.16$ & $0.3 \pm 0.14$ & $2.08 \pm 0.63$ & $57.4 \pm 97.14$ & - \\
\hline & $\begin{array}{l}\text { Summer } \\
\text { (DJF) }\end{array}$ & $0.31 \pm 0.31$ & $0.87 \pm 0.36$ & $0.75 \pm 0.66$ & $571.13 \pm 493.14$ & - \\
\hline & $\begin{array}{l}\text { Autumn } \\
\text { (MAM) }\end{array}$ & $0.04 \pm 0.01$ & $0.42 \pm 0.13$ & $0.02 \pm 0.01$ & $1.32 \pm<0.001$ & - \\
\hline & Winter (JJA) & $0.01 \pm 0.004$ & $0.17 \pm 0.05$ & $0.15 \pm 0.2$ & $1.32 \pm<0.001$ & - \\
\hline \multirow{5}{*}{$\begin{array}{l}\text { Observations - Antarctic } \\
\text { Polar Front }\end{array}$} & Annual & $0.1 \pm 0.05^{1}$ & - & - & - & - \\
\hline & Spring (SON) & $0.04 \pm 0.06^{1}$ & - & - & - & - \\
\hline & $\begin{array}{l}\text { Summer } \\
\text { (DJF) }\end{array}$ & $0.14 \pm 0.03^{1}$ & - & $1.9 \pm 1.37^{3}$ & $42.08 \pm 31.2^{3}$ & - \\
\hline & $\begin{array}{l}\text { Autumn } \\
\text { (MAM) }\end{array}$ & $0.06 \pm 0.05^{1}$ & - & - & - & - \\
\hline & Winter (JJA) & - & - & - & - & - \\
\hline \multirow{5}{*}{$\begin{array}{l}\text { Observations - Antarctic } \\
\text { Peninsula }\end{array}$} & Annual & $0.13 \pm 0.16^{1}$ & - & - & - & - \\
\hline & Spring (SON) & $0.002 \pm 0.003^{1}$ & - & - & - & - \\
\hline & $\begin{array}{l}\text { Summer } \\
\text { (DJF) }\end{array}$ & $0.21 \pm 0.16^{1}$ & $1.25 \pm 1.11^{2}$ & $0.31 \pm 0.09^{2}$ & $28.61 \pm 29.8^{2}$ & - \\
\hline & $\begin{array}{l}\text { Autumn } \\
\text { (MAM) }\end{array}$ & $0.004 \pm 0.01^{1}$ & - & - & - & - \\
\hline & Winter (JJA) & - & - & - & - & - \\
\hline
\end{tabular}

1. Atkinson et al. (2017); 2. Loeb and Santora (2012); 3. Pakhomov and Hunt (2017). 

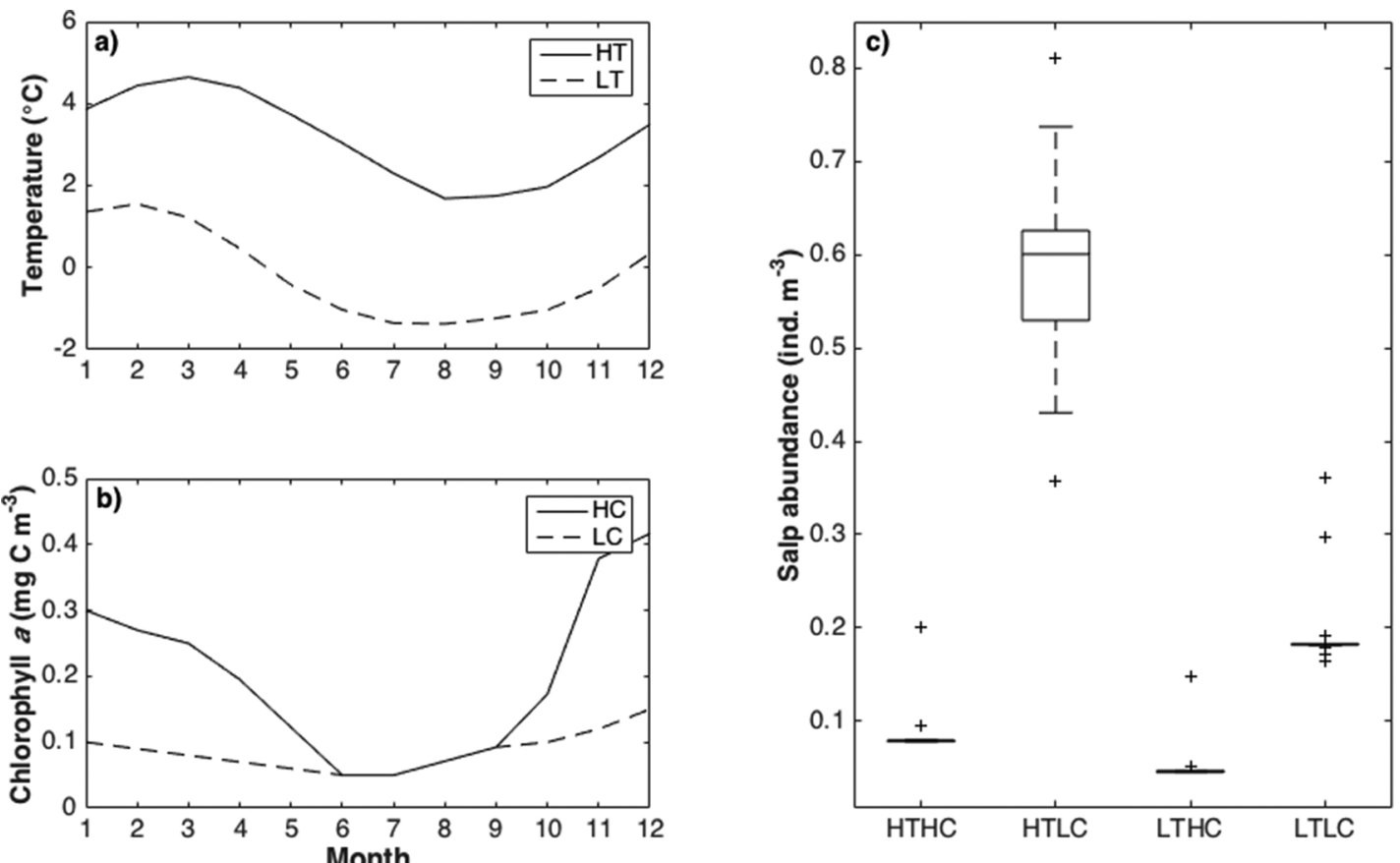

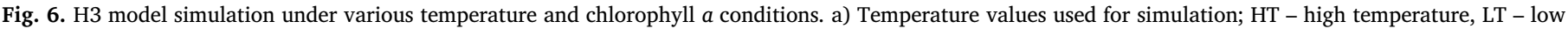

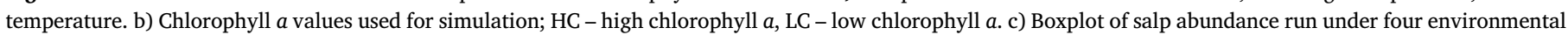

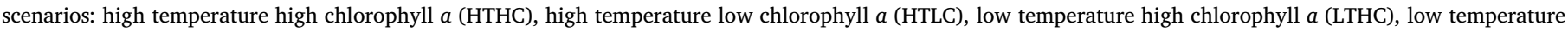

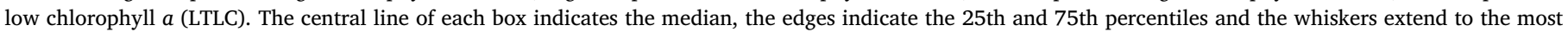
extreme data points. Outliers are plotted using the + symbol.

Table 4

Linear model results for salp biomass and environmental variables. Covariates include annual mean sea surface temperature (SST), spring chlorophyll $a$ concentration (CHLspr), summer SST (SSTsum) and summer chlorophyll a concentration (CHLsum).

\begin{tabular}{lllll}
\hline \multicolumn{1}{l}{ Coefficients } & \multicolumn{3}{l}{} \\
\hline & Estimate & Standard error & $t$ value & $p$ value \\
\hline Intercept & 0.14 & 0.06 & 2.45 & 0.04 \\
SST & -0.1 & 0.08 & -1.27 & 0.25 \\
CHLspr & -0.77 & 0.31 & -2.50 & 0.04 \\
SSTsum & -0.12 & 0.03 & -3.88 & 0.01 \\
CHLsum & 0.70 & 0.22 & 3.17 & 0.02 \\
\hline
\end{tabular}

parameterization for $S$. thompsoni needs to be flexible, and dependent on consumption, particularly as maximum potential growth rates for $S$. thompsoni are unknown. As H3 reproduced the best growth approximation for a $S$. thompsoni population, the following discussion will be based on $\mathrm{H} 3$ results only. In situ growth rates of $S$. thompsoni have only been measured during the austral summer, with observed growth rates varying from 0.23 to $2.82 \mathrm{~mm}$ body length $\mathrm{d}^{-1}$ (Loeb and Santora, 2012; Pakhomov and Hunt, 2017). Growth rates during other seasons are unknown and it is assumed that during winter months oozoids grow slowly and overwinter until conditions improve before releasing buds (Loeb and Santora, 2012). In our model, oozoids grew at mean rates of 1.01-1.12 mm body length $\mathrm{d}^{-1}$ during winter and blastozooids grew at mean rates of 1.04-1.16 mm body length $\mathrm{d}^{-1}$ during summer/autumn. These growth rates are much higher than growth rates observed in January/February by Loeb and Santora (2012), however, when only considering modelled growth rates during January/February, the mean growth rate for the population was $0.53 \mathrm{~mm}$ body length $\mathrm{d}^{-1}$, which is consistent with their observations of $0.41 \mathrm{~mm}$ body length $\mathrm{d}^{-1}$. This suggests that while the growth rates calculated by Loeb and Santora (2012) are correct for January/February, it is inappropriate to assume that the same growth rate is representative of the population throughout different seasons and at different locations. Therefore, while cohort analysis can be a useful way to estimate growth rates in situ, care must be taken when interpreting results.

Growth rates in this model are generally higher for smaller, recently released individuals as filtration rates are higher for smaller individuals - allowing them to consume more per unit body mass compared to larger salps. Hence, the months with higher growth rates in this model corresponded to those with higher proportions of smaller and/or recently released individuals - March to May and November to December. It is necessary to perform cohort analyses or experiments in the field during these seasons, to confirm whether these growth rate relationships can be observed. However, it is evident that based on size composition, previous studies support this hypothesis. Faster growth rates observed by Pakhomov and Hunt (2017) were found in salp populations that were mainly comprised of small individuals ( $>90 \%$ blastozooids smaller than $20 \mathrm{~mm}$ ) whereas in contrast, salp populations sampled by Loeb and Santora (2012) were generally larger (62\% blastozooids smaller than $25 \mathrm{~mm}$ ).

\subsection{Salpa thompsoni community dynamics}

Increased salp abundance and biomass occurred in lower chlorophyll $a$ conditions and at higher temperatures. Despite the availability of chlorophyll $a$ resulting in increased growth rates for salps in this model, faster growth rates resulted in large biomass increases for the population, and thus greater mortality. Low chlorophyll a concentrations could result in increased starvation, however, even when run under very low chlorophyll $a$ conditions starvation did not occur and the salp population could recreate mean observed abundances. Higher temperatures increased the pulsation rate, and hence resulted in increased feeding. This relationship is confirmed through observations where high abundances of $S$. thompsoni generally occur in the warm, low productivity regions of the Southern Ocean (Foxton, 1966; Pakhomov et al., 2002; Atkinson et al., 2004), and suggests why there 
are such large spatial variations in salp abundance across the Southern Ocean.

Demographic properties appear to be more important than environmental fluctuations at driving temporal variations in salp abundance. Reproduction is an important factor influencing salp populations, and in this model the timing of reproduction determines the magnitude of a population. "Salp years" corresponded to years when buds were released later in the summer season in more favorable environmental conditions, which increased survival and growth of the salp population, ultimately resulting in increased production of embryos. Salp swarm magnitude has previously been found to be directly dependent on the number of parents and the amount of buds they release (Daponte et al., 2001; Kawaguchi et al., 2004), suggesting that the factors depicted in this model are appropriate.

This is in contrast to the hypothesis of Loeb and Santora (2012) which suggests that elevated reproduction over at least two generations (two years in their case), as a result of continuously favorable environmental conditions, is required to produce large blooms of Salpa thompsoni in the Southern Ocean. While it is likely that a previously successful generation existing in favorable conditions will also produce a successful generation, the results here suggest that $S$. thompsoni populations may be able to respond to environmental conditions more rapidly, on a weekly or monthly scale, instead of a yearly scale. Exploring the time scale of the factors that drive "salp years" needs to be the focus of future work on $S$. thompsoni population dynamics, particularly under a changing climate.

\subsection{Model limitations}

Model parameters chosen in this model fall well within empirical ranges, and while there are some uncertainties in processes depicted in this model, the model results were robust to variation. Mortality and embryo release date were found to be the most influential factors driving variations in salp abundance. The effect of mortality on salp abundance is expected, and while no mortality values exist for Salpa thompsoni, the values used in this study are within published ranges for salps and other gelatinous zooplankton. Embryo and bud release dates remain the most uncertain parameters within this model, and have the largest impact on salp abundance. Varying embryo and bud release dates by \pm 1 month had a negligible effect on seasonal salp abundance, yet the effect on interannual salp abundance is more significant. It is unknown which factors drive embryo and bud release in situ, however it is generally thought that embryo release occurs in autumn, bud release in spring and reproductive releases only occur once a year (Foxton, 1966). This principle is assumed in this model, and while it may be likely as there are clear seasonal trends in $S$. thompsoni abundance and timed reproduction would increase the success rate for the fertilisation of young blastozooids (Miller and Cosson, 1997), variations in bud release time had a significant effect on interannual salp abundance. Additionally, model runs without a seasonal limitation on embryo/bud release indicated that there are enough chlorophyll $a$ resources to support multiple reproductive releases per year and much faster generation times. Thus, future empirical work should explore the environmental factors driving the onset of both embryo and bud release in salp populations and determine how often reproduction occurs within a year.

\subsection{Concluding remarks}

Understanding the factors driving variations in Salpa thompsoni populations is integral when trying to examine the likelihood of a $S$. thompsoni range expansion into krill-habitats. This model could successfully recreate the observed trends in seasonal and interannual $S$. thompsoni populations at two locations in the Southern Ocean, suggesting that this is a possible model scenario explaining the empirical data. Salp abundance and biomass are strongly influenced by bottom- up forcing, with more successful salp populations occurring in warm, low productive environments. $S$. thompsoni growth rates were determined to be higher than previously estimated, with a mean growth rate of $\sim 1$ mm body length $\mathrm{d}^{-1}$, but a seasonal variation across almost two orders of magnitude. Analysis of different hypothesis scenarios identified that it is necessary that growth and reproductive rates are flexible, particularly seasonally, in order for the salp population to adapt to varying environmental conditions. This flexibility may explain how Southern Ocean salp populations can be so successful, even in very low food environments. Future empirical work is needed to elucidate this growth rate hypothesis, particularly as it is likely that maximum potential growth rates for $S$. thompsoni are much greater than values currently determined from in situ measurements.

\section{Acknowledgements}

This work was supported by the University of British Columbia. We also thank the National Sciences and Engineering Research Council (NSERC) Discovery Grant awarded to EAP and the Pekris BMBF Project 03F0746B awarded to BM and JG for partial support of this work. We are grateful to the two anonymous reviewers for their insightful comments that helped to clarify this manuscript.

\section{Appendix A. Supplementary data}

Supplementary material related to this article can be found, in the online version, at doi:https://doi.org/10.1016/j.ecolmodel.2018.08. 017.

\section{References}

Alldredge, A.L., Madin, L.P., 1982. Pelagic tunicates: unique herbivores in the marine plankton. Bioscience 32, 655-663.

Andersen, V., Nival, P., 1986. A model of the population-dynamics of salps in coastal waters of the Ligurian Sea. J. Plankton Res. 8, 1091-1110.

Atkinson, A., Siegel, V., Pakhomov, E., Rothery, P., 2004. Long-term decline in krill stock and increase in salps within the Southern Ocean. Nature 432, 100-103.

Atkinson, A., Hill, S.L., Pakhomov, E., Siegel, V., Anadon, R., Chiba, S., Daly, K.L., Downie, R., Fielding, S., Fretwell, P., Gerrish, L., Hosie, G.W., Jessop, M.J., Kawaguchi, S., Krafft, B.A., Loeb, V.J., Nishikawa, J., Peat, H.J., Reiss, C.S., Ross, R.M., Langdon, B., Quetin, L.B., Schmidt, K., Steinberg, D.K., Subramaniam, R.C., Tarling, G.A., Ward, P., 2017. KRILLBASE: a circumpolar database of Antarctic krill and salp numerical densities, 1926-2016. Earth Syst. Sci. Data 9, 193-2107.

Bruland, K.W., Silver, M.W., 1981. Sinking rates of fecal pellets from gelatinous zooplankton (salps, pteropods, doliolids). Mar. Biol. 63, 295-300.

Casareto, B.E., Nemoto, T., 1986. Salps of the Southern Ocean (Australian Sector) During the 1983-84 Summer, With Special Reference to the Species Salpa Thompsoni, Foxton 1961, vol. 40. Memoirs of National Institute of Polar Research, pp. 221-239 Special Issue.

Chiba, S, Horimoto, N., Satoh, R., Yamaguchi, Y., Ishimaru, T, 1998, Macrozooplankton distribution around the Antarctic divergence off Wilkes Land in the 1996 austral summer: with reference to high abundance of Salpa thompsoni. Proc. NIPR Symp. Polar Biol. 11, 33-50.

Chiba, S., Ishimaru, T., Hosie, G.W., Wright, S.W., 1999. Population structure change of Salpa thompsoni from austral mid-summer to autumn. Polar Biol. 22, 341-349.

Daponte, M.C., Capitanio, F.L., Esnal, G.B., 2001. A mechanism for swarming in the tunicate Salpa thompsoni (Foxton, 1961). Antarct. Sci. 13, 240-245.

Deibel, D., 1982. Laboratory determined mortality, fecundity and growth-rates of Thalia democratica Forskal and Dolioletta gegenbauri Uljanin (Tunicata, Thaliacea). J. Plankton Res. 4, 143-153.

Deibel, D., 1985. Clearance rates of the salp Thalia democratica fed naturally occurring particles. Mar. Biol. 86, 47-54.

Dubischar, C.D., Bathmann, U.V., 1997. Grazing impact of copepods and salps on phytoplankton in the Atlantic sector of the Southern Ocean. Deep Sea Res. Part II Top. Stud. Oceanogr. 44, 415-433.

Fischer, G., Futterer, D., Gersonde, R., Honjo, S., Ostermann, D., Wefer, G., 1988. Seasonal variability of particle flux in the Weddell Sea and its relation to ice cover. Nature 335, 426-428.

Foxton, P., 1966. The distribution and life-history of Salpa thompsoni Foxton with observations on a related species, Salpa gerlachei Foxton. Discov. Rep. 34, 1-116.

Graham, W.M., Pagès, F., Hamner, W.M., 2001. A physical context for gelatinous zooplankton aggregations: a review. Hydrobiologia 451, 199-212.

Harbison, G.R., Campenot, R.B., 1979. Effects of temperature on the swimming of salps (Tunicata, Thaliacea): implications for vertical migration. Limnol. Oceanogr. 24, 1081-1091.

Harbison, G., Gilmer, R., 1976. The feeding rates of the pelagic tunicate Pegea confederata 
and two other salps. Limnol. Oceanogr. 21, 517-528.

Henschke, N., Pakhomov, E.A., Latitudinal variations in Salpa thompsoni reproductive fitness (in review).

Henschke, N., Bowden, D.A., Everett, J.D., Holmes, S.P., Kloser, R.J., Lee, R.W., Suthers, I.M., 2013. Salp-falls in the Tasman Sea: a major food input to deep sea benthos. Mar. Ecol. Prog. Ser. 491, 165-175.

Henschke, N., Everett, J.D., Doblin, M.A., Pitt, K.A., Richardson, A.J., Suthers, I.M., 2014. Demography and interannual variability of salp swarms (Thalia democratica). Mar. Biol. 161, 149-163.

Henschke, N., Smith, J.A., Everett, J.D., Suthers, I.M., 2015. Population drivers of a Thalia democratica swarm: insights from population modelling. J. Plankton Res. 37, 1074-1087.

Henschke, N., Everett, J.D., Richardson, A.J., Suthers, I.M., 2016. Rethinking the role of salps in the ocean. Trends Ecol. Evol. 31, 720-733.

Henschke, N., Stock, C.A., Sarmiento, J.L., 2018. Modeling population dynamics of scyphozoan jellyfish (Aurelia spp.) in the Gulf of Mexico. Mar. Ecol. Prog. Ser. 591, 167-183.

Heron, A.C., 1972. Population ecology of a colonizing species-pelagic tunicate Thalia democratica. 1. Individual growth-rate and generation time. Oecologia 10, 269-293.

Heron, A.C., Benham, E.E., 1984. Individual growth rates of salps in three populations. J. Plankton Res. 6, 811-828.

Huntley, M.E., Sykes, P.F., Marin, V., 1989. Biometry and trophodynamics of Salpa thompsoni Foxton (Tunicata, Thaliacea) near the Antarctic Peninsula in austral summer, 1983-1984. Polar Biol. 10, 59-70.

Iguchi, N., Ikeda, T., 2004. Metabolism and elemental composition of aggregate and solitary forms of Salpa thompsoni (Tunicata: Thaliacea) in waters off the Antarctic Peninsula during austral summer 1999. J. Plankton Res. 26, 1025-1037.

Iversen, M.H., Pakhomov, E.A., Hunt, B.P.V., van der Jagt, H., Wolf-Gladrow, D., Klaas, C., 2017. Sinkers or floaters? Contribution from salp pellets to the export flux during a large bloom event in the Southern Ocean. Deep Sea Res. Part II 138, 116-125.

Kawaguchi, S., Siegel, V., Litvinov, F., Loeb, V., Watkins, J., 2004. Salp distribution and size composition in the Atlantic sector of the Southern Ocean. Deep Sea Res. Part II Top. Stud. Oceanogr. 51, 1369-1381.

Lee, R.F., Hagen, W., Kattner, G., 2006. Lipid storage in marine zooplankton. Mar. Ecol. Prog. Ser. 307, 273-306.

Loeb, V.J., Santora, J.A., 2012. Populaton dynamics of Salpa thompsoni near the Antarctic Peninsula: growth rates and interannual variations in reproductive activity (1993-2009). Prog. Oceanogr. 96, 93-107.

Loeb, V., Siegel, V., HolmHansen, O., Hewitt, R., Fraser, W., Trivelpiece, W., Trivelpiece, S., 1997. Effects of sea-ice extent and krill or salp dominance on the Antarctic food web. Nature 387, 897-900.

Miller, R.L., Cosson, J., 1997. Timing of sperm shedding and release of aggregates in the salp Thalia democratica (Urochordata: Thaliacea). Mar. Biol. 129, 607-614.

NASA, 2015. Sea-Viewing Wide Field-of-View Sensor (SeaWiFS) Ocean Color Data.
Available at. https://oceandata.sci.gsfc.nasa.gov/SeaWiFS/Mapped/Monthly/9km/ chlor_a.

Ohman, M.D., Runge, J.A., Durbin, E.G., Field, D.B., Niehoff, B., 2002. On birth and death in the sea. Hydrobiologia 480, 55-68.

Ono, A., Moteki, M., 2013. Spatial distributions and population dynamics of two salp species, Ihlea racovitzai and Salpa thompsoni, in the waters north of Lützow-Holm Bay (East Antarctica) during austral summers of 2005 and 2006. Polar Biol. 36, 807-817.

Oviatt, C.A., Kremer, P.M., 1977. Predation on the ctenophore, Mnemiopsis leidyi, by Butterfish, Peprilus triacanthus, in Narragansett Bay, Rhode Island. Chesap. Sci. 18, 236-240.

Pakhomov, E., Froneman, P.W., 2004. Zooplankton dynamics in the eastern Atlantic sector of the Southern Ocean during the austral summer 1997/1998-part 2: grazing impact. Deep Sea Res. Part II 51, 2617-2631.

Pakhomov, E.A., Hunt, B.P.V., 2017. Trans-Atlantic variability in ecology of the pelagic tunicate Salpa thompsoni near the Antarctic Polar Front. Deep Sea Res. Part II 138, $126-140$.

Pakhomov, E.A., Froneman, P.W., Perissinotto, R., 2002. Salp/krill interactions in the Southern Ocean: spatial segregation and implications for the carbon flux. Deep Sea Res. Part II 49, 1881-1907.

Pakhomov, E.A., Dubischar, C.D., Hunt, B.P.V., Strass, V., Cisewski, B., Siegel, V., von Harbou, L., Gurney, L., Kitchener, J., Bathmann, U., 2011. Biology and life cycles of pelagic tunicates in the Lazarev Sea, Southern Ocean. Deep Sea Res. Part II 58, $1677-1689$.

Perissinotto, R., Pakhomov, E.A., 1998a. Contribution of salps to carbon flux of marginal ice zone of the Lazarev Sea, Southern Ocean. Mar. Biol. 131, 25-32.

Perissinotto, R., Pakhomov, E.A., 1998b. The trophic role of the tunicate Salpa thompsoni in the Antarctic marine ecosystem. J. Mar. Syst. 17, 361-374.

Raskoff, K.A., Sommer, F.A., Hamner, W.M., Cross, K.M., 2003. Collection and culture techniques for gelatinous zooplankton. Biol. Bull. 204, 68-80.

Reynolds, R.W., Smith, T.M., Liu, C., Chelton, D.B., Casey, K.S., Schlax, M.G., 2007. Daily high-resolution-blended analyses for sea surface temperature. J. Clim. 20, 5473-5496.

Ross, R.M., Quetin, L.B., 1996. Distribution of Antarctic Krill and Dominant Zooplankton West of the Antarctic Peninsula, vol. 70. Foundations for Ecological Research West of the Antarctic Peninsula, pp. 199-217.

Smith Jr., K.L., Sherman, A.D., Huffard, C.L., McGill, P.R., Henthorn, R., Von Thun, S., Ruhl, H.A., Kahru, M., Ohman, M.D., 2014. Large salp bloom export from the upper ocean and benthic community response in the abyssal northeast Pacific: day to week resolution. Limnol. Oceanogr. 59, 745-757.

Steele, J.H., Henderson, E.W., 1993. The significance of interannual variability. In: Evans, G.T., Fasham, M.J.R. (Eds.), Towards a Model of Ocean Biogeochemical Processes. Springer Berlin Heidelberg, Berlin, Heidelberg, pp. 237-260.

von Harbou, L., 2009. Trophodynamics of Salps in the Atlantic Southern Ocean. University of Bremen. 